\title{
Importancia y determinantes de la asociación productiva agrícola: el cultivo de ñame en el caribe colombiano
}

\author{
Importance and determinants of the agricultural \\ productive association: yam cultivation in the \\ Colombian Caribbean
}

Henry Mendoza-Crespo ${ }^{1}$

Universidad de la Costa, Barranquilla, Colombia hmendozal4@cuc.edu.co

https://orcid.org/0000-0002-9792-1070

Recibido: 15-02-20

Aprobado: 10-06-20 


\section{Resumen}

El objetivo principal de este estudio es identificar los determinantes productivos que inciden en la asociación de los productores de ñame de la región Caribe colombiana. La base de datos utilizada en esta investigación es el Censo Nacional Agropecuario 2014, desarrollado y suministrado por el Departamento Nacional de Estadística (DANE). El método de estimación econométrica utilizado es el modelo probit. Se observa que cada departamento posee diferencias en los factores que afectan a la membresía. Por último, se concluye que la asociación productiva es una manera en la que el productor puede obtener financiamiento, insumos, información y poder de negociación.

Palabras clave: cooperativas; ñame; Caribe; membresía.

Clasificación JEL: J54, P13, Q15, C25.

\section{Abstract}

The main objective of this paper is to identify productive determinants that have an influence in the association of yam producers in the Caribbean region of Colombia. The database used in this research is the Censo Nacional Agropecuario 2014, developed and supplied by the Departamento Nacional de Estadística (DANE). The method of econometric estimation used is the probit model. It is observed that each department has differences in factors that affect membership. Lastly, it is concluded that the productive association is a way in which the producer can get financing, input, information and negotiation power.

Keywords: cooperative; yam; Caribbean; membership.

JEL Classification: J54, P13, Q15, C25.

¿Cómo citar este artículo? / How to quote this article?

Mendoza-Crespo, H. y Ortiz-Velásquez, M. (2020). Determinantes de la asociación productiva del cultivo de ñame en el caribe colombiano. Sociedad y economía, (41), 88-108. https://doi.org/10.25100/sye.voi41.8932 


\section{Introducción}

El ñame es un tubérculo que pertenece a la familia Dioscoreaceae. Dicha familia cuenta con 600 a 900 especies, y estas poseen un alto potencial de explotación económico (González, 2012). Los diferentes tipos de ñame se ubican en el cuarto lugar de importancia a nivel mundial entre las plantas conformadas por raíces y tubérculos (Borges et al., 2011). Según Reina (2012), el ñame se ha considerado un sustituto ideal de la papa y la yuca, y tanto su producción como su consumo se realiza principalmente en países en desarrollo, como los del continente africano, islas de las Antillas caribeñas y en suramericanos como Colombia.

Del mismo modo, Reina (2012) manifiesta que Colombia cuenta con una tasa de rendimiento del cultivo de 28,3 toneladas por hectárea cultivada; ocupa el puesto 12, entre los países productores, con 395.374 toneladas en el año 2010; y el 90\% de la producción del país la proporciona la región Caribe. Colombia es el país con el rendimiento del cultivo de ñame más alto a nivel mundial, debido a factores dentro del proceso productivo, como el tipo de semilla, suelos y técnicas de siembra (Acevedo et al., 2015). La mayor parte de la producción se desarrolla en los departamentos de Bolívar, Córdoba y Sucre (Álvarez, 2000). El ñame es cultivado por pequeños y medianos agricultores, constituyéndose como fuente importante en el empleo rural (Méndez et al., 2013).

Adicionalmente, al menos 20.000 familias de los departamentos mencionados se dedican a la producción del ñame (Doncel y Pérez, 2017). Este tubérculo se utiliza principalmente para la dieta en la región, debido a que su principal componente es el almidón, que contiene altas cantidades de carbohidratos (Pinzón et al., 2013). Por otra parte, se ha documentado que los diferentes tipos de ñames (Dioscorea), considerados como verdaderos, se han empleado en la industria farmacéutica, con la finalidad de tratar problemas de salud como la diabetes, la dismenorrea, inflamaciones, etc. (Ramos et al., 2015).

El ñame se ha mostrado como un producto agrícola con un potencial de exportación interesante. Según la Revista Dinero (2016), la venta de ñame pasó de US \$22.847, en 2012, a cerca de 2,7 millones, en el año 2015. A pesar de la importancia social y económica que tiene en la región Caribe, el cultivo se ha visto afectado por la aparición del hongo Colletotrichum Gloesporoides, causante de la antracnosis. La antracnosis es una enfermedad que causa lesiones en el peciolo, tallo y hojas; dichas lesiones son oscuras. Así mismo, en el tejido foliar aparecen manchas con diferentes patrones, con colores pardo rojizo, ocasionando pérdidas del $90 \%$ de la cantidad recolectada (Amusa et al., 2003).

En el año 1989, en Colombia, más de 25.000 hectáreas de ñame se vieron afectadas por una infección de antracnosis. Como resultado, el área sembrada de cultivo de ñame, en 1990, disminuyó hasta alcanzar 1.000 hectáreas (Cerón et al., 2006). La región Caribe colombiana es la región del país donde hay la mayor incidencia de esta enfermedad, generando pérdidas que llegan a ser del $85 \%$ de la producción (Green et al., 2000). Además de los problemas sanitarios que tiene el cultivo, también existen problemas asociados a la falta de desarrollo tecnológico.

El ñame es cultivado con un bajo nivel de desarrollo tecnológico, por lo cual, el producto agrícola se caracteriza por ser de consumo regional, sin poder aprovecharse bajo un esquema de producción industrial (Hata et al., 2003). Así mismo, el cultivo se realiza de manera artesanal, empleando mano de obra familiar en pequeñas áreas y existe poca o ninguna participación institucional en temas referentes a investigación y asistencia técnica, causando que exista una baja rentabilidad (Arrieta et al., 2017).

Dado los problemas expuestos, se ha sugerido como estrategia para el manejo de dichos problemas la formación de asociaciones entre productores. La asociación con fines de cooperación facilita el acceso a capital humano, desarrollo de mercados y mejora de confianza (Alesina y La Ferrara, 2000). Por otro lado, las asociaciones permiten que sus miembros reciban información de cómo llevar a cabo su proceso productivo. Así mismo, la cooperación permite que los agricultores puedan acceder a nuevas tecnologías y maquinarias; utilizar técnicas e 
insumos más amigables con el medio ambiente. En consideración de lo anterior, el presente estudio tiene como propósito dar respuesta a la pregunta de investigación ¿cuáles son los determinantes productivos que impactan en el ingreso a la asociación en los agricultores de ñame en la región Caribe?

Para ello, el documento se encuentra estructurado en siete secciones. La primera corresponde a la introducción, donde se detalla la importancia económica, los principales problemas asociados a la producción de ñame y las formas en que se puede aprovechar la asociación productiva. En la siguiente sección, se hace una revisión de literatura, donde se describen investigaciones disponibles. Posteriormente, se desarrolla el marco teórico acerca de las cooperativas y su enfoque en la Nueva Economía Institucional. En la cuarta sección, se describen los materiales y métodos utilizados. Luego, se procede al análisis descriptivo de algunas variables. Después, al análisis empírico. Finalmente, se realizan las conclusiones y algunas recomendaciones.

\section{Revisión de literatura}

Se seleccionan 17 trabajos que identifican cuáles son las razones que determinan el ingreso o afiliación a una asociación productiva en los productores agrícolas. Entre estas razones, se encuentra el acceso al crédito. En el estado Delta de Nigeria, Ofuoku y Urang (2009) enmarcan los beneficios obtenidos de la acción colectiva. La muestra está conformada por 1.190 agricultores. La aproximación teórica empleada es el análisis de orden de rango de Spearman. Los autores encuentran que los miembros que hicieron parte de una cooperativa de agricultores obtuvieron acceso al crédito, servicios de extensión e insumos más baratos. Otras razones para asociarse son la facilidad de realizar mercadeo directo, determinación de precios e intercambio de ideas.

Otro factor identificado, en la propensión a asociarse, es el poseer tierras destinadas para la agricultura. Francesconi y Heerink (2010) toman una muestra de más de 7.000 mil hogares etíopes dedicados a la agricultura. Utilizan un modelo probit para el análisis de la membresía a cooperativas agrícolas, y la técnica Propensity Score Machine para analizar el impacto que tiene pertenecer a cooperativas sobre los miembros. Los autores encuentran que la variable "cantidad de hectáreas del agricultor" tiene un comportamiento cóncavo. Es decir, a medida que aumentan el número de hectáreas, la propensión a juntarse crece. Aunque dichos aumentos en la probabilidad son cada vez menores, hasta el punto en que el agricultor cuenta con nueve hectáreas; a partir de ese momento, contar con más hectáreas disminuye la probabilidad de asociarse.

Además, la investigación muestra que los miembros asociados a cooperativas son terratenientes de nivel medio, ubicados en áreas con un alto potencial para la comercialización agrícola. Por lo tanto, las cooperativas no pueden ser vistas como medios para asegurar la participación de los más pobres entre los pobres. Del mismo modo, Agbonlahor et al. (2012) desarrolló un estudio en el suroeste de Nigeria con una muestra de 326 personas. La técnica utilizada fue el modelo tobit. Uno de los principales hallazgos de este trabajo es que el ingreso de los asociados fue más alto que el de aquellos que no están asociados. Además, la intensidad de la participación, medida por actividades grupales por año dentro de una cooperativa, está influenciada por el género, área cultivada y estado social del individuo. Así mismo, los agricultores que hacen parte de proyectos comunales, que son propietarios de terrenos y están casados, tienen una mayor intensidad de participación.

Por otra parte, Ma y Abdulai (2016) analizan el impacto que tiene el hecho de pertenecer a una cooperativa sobre los indicadores de rendimiento en las UPA, como el ingreso por hogar del agricultor y rendimiento de la producción de manzanas. En el estudio, se utiliza información de 481 hogares agrícolas. Respecto al análisis de la membresía, los autores utilizan un modelo de tipo Probit. Se encontró que contar con más área de cultivo, tener computadora y un número de días de trabajo más alto por unidad de área, aumenta la probabilidad sobre la 
membresía de tipo productivo. Adicionalmente, el estudio demuestra que pertenecer a una cooperativa tiene efectos sobre los indicadores mencionados y los UPA de pequeña escala tienden a beneficiarse más de las cooperativas que las fincas medianas y grandes.

Entre los factores investigados, se encuentra que el número de trabajadores pertenecientes al hogar o contratados impacta en la propensión a juntarse a una asociación agrícola. En el país de Ruanda, los autores Verhofstadt y Maertens (2015) investigan si las cooperativas agrícolas pueden reducir la pobreza. Para ello, utilizan una muestra aleatoria, estratificada en 3 niveles, de 401 hogares agrícolas. Los datos son empleados en un modelo probit, para identificar los factores que inciden en la membresía, y se aplica la técnica de Propensity Score Matching para analizar el impacto sobre la pobreza. Los hallazgos muestran que un mayor número de hectáreas, contar con un trabajador del hogar del productor y tener más años de educación, aumentan la probabilidad de asociarse. En cambio, cuando el productor experimenta una hora adicional para transportarse, desde el mercado hasta la parcela, disminuye la probabilidad de asociarse. Además, se encuentra que la membresía en cooperativas incrementa el ingreso y que los efectos son mayores para granjas más grandes y en áreas más remotas.

Respecto a los países europeos, Szabolcs et al. (2016), en su investigación, evalúan el desarrollo de múltiples formas de cooperación de tipo horizontal y vertical en Hungría. Los autores utilizan una muestra de 1.000 agricultores. Se desarrolla una técnica denominada point-biserial para analizar la correlación entre las formas de cooperación, los parámetros y actitudes estudiados. La membresía, medida como una variable categórica entre o y l, está relacionada positivamente por el área destinada al uso agrícola, número de trabajadores, y la inversión realizada en el proceso productivo. En contraste, la membresía está relacionada negativamente con el hecho de ser productor masculino. Los autores recomiendan que las relaciones de tipo informal se conviertan en relaciones formales por medio de asociaciones, alianzas y redes.

Por otro lado, la variable control de plagas puede aumentar o disminuir la propensión a juntarse a una asociación productiva. En Estados Unidos, Munasib y Jordan (2011) estudian si el capital social, en forma de participación comunitaria, afecta las elecciones de los agricultores, en el uso de prácticas agrícolas sostenibles. El estudio emplea información de 317 hogares agrícolas. Los autores emplean un modelo de tipo probit. Se identifica que los agricultores que cuentan con un mayor número de membresías en asociaciones poseen una mayor propensión al uso del control ambiental de plagas.

En el caso colombiano, Rómulo (2017) identifica los determinantes del cooperativismo agrícola en la región Caribe. El autor emplea información de los productores agropecuarios de seis departamentos que conforman dicha región. La aproximación econométrica que utiliza es el modelo logit. El autor encuentra que una mayor área cosechada disminuye la propensión a asociarse en cuatro departamentos. Las variables control de plagas y uso de fertilizantes también tienen un efecto negativo sobre la propensión a asociarse. El acceso al crédito se mostró como una razón importante y positiva para asociarse.

Respecto a la categoría de cultivos comerciales, se identifican cuatro estudios donde se observan los efectos que tiene el hecho de asociarse. En China, los autores Zheng et al. (2012) realizan un estudio para investigar los determinantes de la percepción de los agricultores y su decisión de participar en cooperativas, con una muestra de 819 hogares agrícolas ubicados en 9 distritos de la provincia de Jiling. La técnica econométrica utilizada es un modelo probit bivariado. El estudio muestra que los niveles de riesgos asociados a la producción, los costos operacionales y contar con cultivos comerciales aumentan la propensión a asociarse. Además, cuando el cultivo es usado para la subsistencia, tiene un efecto que disminuye la probabilidad de asociarse. 
En Benín, Mensah et al. (2012) evaluaron los determinantes del compromiso con las cooperativas agrícolas en los agricultores de nueces. Para lo cual, tomaron una muestra de 277 agricultores. Se desarrolló un modelo logit donde identifican que las razones para comprometerse con una cooperativa son: creen en el poder de negocio; no tienen preferencias por el crédito comercial; son pequeños agricultores y tienen razones psicosociales para hacer parte de una cooperativa. Además, los miembros que negocian con sus cooperativas pueden vender su producto a un precio mayor respecto a los que no son cooperados.

Del mismo modo, Cechin et al. (2013) desarrollan una investigación en Brasil para una cooperativa agrícola. Los estudios se dividen en cuatro dimensiones organizativas: mercados, jerarquías, comunidad y democracia. Los datos son tomados de una cooperativa de 27 productores de vegetales, 58 productores destinados al engorde de pollos y 63 especializados en la producción de soya. La estrategia empírica utilizada es el análisis de componentes principales con rotación Varimax y el análisis de componentes de Chronbach. La variable dependiente está relacionada con la variable categórica de hacer parte de la acción colectiva. El estudio identifica que los miembros que tuvieron mayores incentivos de mercado estaban más comprometidos con la acción colectiva. Los miembros con unidades productoras agropecuarias estaban menos comprometidos con la acción colectiva.

En Eslovaquia, Lazíková et al. (2014) investigan si las entidades comerciales asociadas a los grupos de productores fueron más exitosas que aquellas no asociadas. Los autores utilizan una prueba de medias para observar si existen diferencias significativas entre los grupos. Entre los hallazgos, se observa que los asociados reciben ingresos más altos y costos más bajos por hectáreas, que los no asociados. Además, los productores asociados son más eficaces al momento de mercadear que los no asociados. Por otra parte, se observa que las cooperativas ubicadas en la región de Nitra se enfocan en las actividades de mercadeo. En cambio, las de la región de Zolina se enfocan en la disminución de costos.
Del mismo modo, Abate et al. (2014) utilizan una muestra de 1.638 hogares agrícolas etíopes para identificar los determinantes de la membresía en las cooperativas agrícolas y el impacto de las cooperativas sobre la eficiencia técnica de los pequeños agricultores. La aproximación empírica empleada es un modelo probit, junto con la técnica de Propensity Score Matching. Se demuestra que existe un impacto significativo y positivo de las cooperativas sobre el nivel de eficiencia de los miembros. Así mismo, el hecho de contar con más bueyes, mayor número de miembros en el hogar y cultivos comerciales, aumenta la propensión a pertenecer a una cooperativa. Por el contrario, la edad del agricultor y los ingresos provenientes de actividades no agrícolas, disminuyen la propensión. La variable "número de hectáreas" tiene un comportamiento de tipo cóncavo.

La variable "educación" es utilizada dentro de la literatura para observar si cuenta con algún tipo de impacto. Mabuza et al. (2015) intentan examinar las probables implicaciones que tienen las formas organizativas sobre el desempeño colectivo de los productores de champiñones en Suazilandia. En el estudio, se utiliza información concerniente a 271 productores. En la aproximación teórica, utilizan un modelo logit para analizar la propensión a asociarse y la técnica Propensity Score Matching. Los autores identifican que un nivel educativo más alto del productor, recibir información sobre su proceso productivo y considerarse no pobre, impacta de manera positiva en la propensión a asociarse. Además, los autores sugieren que el mercadeo de champiñones se puede coordinar, dado que los miembros comienzan el ciclo productivo al mismo tiempo.

Por otra parte, dentro de la literatura revisada se encuentra que las amistades y relaciones interpersonales inciden en la propensión a la asociación productiva. En la región de Nanjing, China, los investigadores Ito et al. (2012) examinan los efectos producidos por pertenecer a una cooperativa agrícola y los servicios de extensión que reciben financiamiento del gobierno. La cooperativa estudiada no tiene en cuenta la participación de los pequeños agricultores. La muestra está conformada por 318 hogares productores de sandía. La técnica econométrica utilizada para el análisis de 
la membresía es el modelo probit y, para el análisis de los efectos, es el Propensity Score Matching. Los resultados muestran que, por cada vecino del agricultor que haga parte de una cooperativa, aumenta la propensión del agricultor a juntarse. Además, la variable "área cultivada" tiene un comportamiento cóncavo. Así mismo, el análisis econométrico muestra que los servicios de extensión generan un efecto moderado sobre el ingreso de la UPA.

Por otra parte, Nugusse et al. (2013) toman una muestra aleatoria de 400 hogares ubicados en la región del Tigray, Etiopia, para analizar los factores que inciden en que la población rural se junte a las cooperativas. La técnica empírica empleada es el modelo probit. Entre los hallazgos encontrados, se observa que las personas que participan en las reuniones de cooperativas hacen parte de otro tipo de asociaciones. El nivel de educación de la cabeza del hogar y el acceso a crédito aumentan la probabilidad de enrolarse a una cooperativa. En cambio, tener acceso a información, ser propietario del terreno y el tamaño del hogar, disminuyen la probabilidad de asociarse.

Koutsou et al. (2014) examinan el capital social en un grupo de 1.265 agricultores griegos, con el fin de suministrar una explicación sobre los procesos que causan que el capital social desempeñe un rol importante en el desarrollo de la comunidad. Por medio de un modelo logit multinomial, se analizan las características de agricultor innovador, convencional y latente. Los autores manifiestan que la participación en organizaciones voluntarias es limitada, lo que se traduce en poco acceso a la innovación. Los agricultores mostraron más confianza en personas particulares y poca en las instituciones. Es decir, que existe preferencia por las relaciones informales.

\section{Marco teórico}

Con el objetivo de identificar los determinantes de la asociación productiva de los agricultores de ñame, en la región Caribe colombiana, se utiliza un marco teórico que se enfoca desde la perspectiva del capital social y cómo esta se relaciona con la teoría del modelo de desarrollo endógeno.

\subsection{Capital Social}

Los primeros autores que se encargaron de desarrollar un concepto en el cual se pudiese enmarcar el capital social fueron Bourdieu, Coleman y Putnam (Vargas, 2002). Por su parte, Bourdieu (1986) plantea que el capital social es la suma de los recursos presentes y los que son de tipo potencial. Es decir, aquellos que conforman una red con características de institucionalidad, donde se cuenta con conocimiento y reconocimiento de los miembros.

Coleman (1990) expone el capital social como la valoración que tienen, para los integrantes, aspectos que constituyen la estructura social, como los recursos con los cuales pueden lograr sus objetivos. Asimismo, Coleman (1990) identifica múltiples formas de capital social: relaciones entre amigos que generan fuente de información y normativas ajustadas a incentivos. Del mismo modo, este autor manifiesta que, en el capital social, los beneficios los absorben los miembros y los no miembros.

Por otro lado, Putnam (1993) se refiere al capital social como un conglomerado de redes y normativas, que permiten la cooperación para beneficios de sus integrantes. Dentro del capital social se derivan una serie de beneficios. Según Alesina y La Ferrara (2000), la cohesión dentro de un grupo causa que existan relaciones entre los miembros que contribuyen a la transferencia de conocimiento, creación de relaciones de confianza y mejoras en el desempeño de los mercados. Así mismo, Glaeser et al. (2002) muestran que, al hacer parte de la cohesión social, se contribuye a la formación de capital social, debido a que la cercanía entre los individuos crea confianza y cooperación.

A continuación, se expondrá cómo la interacción entre individuos genera modelos de desarrollo endógeno por medio de la cooperación.

\subsection{Cooperativas agrícolas - Modelo de desarrollo endógeno}

El modelo neoclásico de cooperativa ha sido criticado, debido a la cantidad de supuestos que en la realidad son difíciles de cumplir. 
El modelo no explica cuál es la razón de la existencia de las firmas, y cómo los recursos que constituyen la organización son alentados para lograr el máximo beneficio (Sykuta y Chaddad, 1999). Del mismo modo, Sykuta y Chaddad (1999) manifiestan que el modelo neoclásico no permite responder preguntas como ¿cuándo hay cambios en los mercados? ¿A qué se debe la evolución de los mercados? ¿Cuál es la composición interna de las instituciones que se encargan de respaldar las actividades de mercado?

Ante los diferentes problemas encontrados con el modelo neoclásico, surgen teorías que han intentado explicar el funcionamiento de la cooperación productiva entre personas. Entre estas se encuentra la teoría del desarrollo rural endógeno. Anteriormente, se consideraba que el desarrollo de los sistemas productivos se generaba en los principales centros urbanos, y las zonas rurales tenían como función abastecer de insumos a dichos centros (Bel y Cabaleiro, 2002).

Por lo tanto, las políticas públicas en temas de desarrollo favorecían a los centros urbanos, y las zonas rurales debían ajustarse a estas políticas. Lo anterior conlleva a que se afectara el proceso de desarrollo rural, debido a que no se tenía en cuenta la heterogeneidad presente en la zona rural. Luego, en los años 70 , los esfuerzos se centran en cambiar el modelo exógeno, para abrir paso al modelo de desarrollo endógeno, o modelo desde abajo (Bel y Cabaleiro, 2002).

El desarrollo endógeno es definido por Vázquez (1999) como la capacidad de emprender de la comunidad, para poder llevar a cabo su progreso, utilizando sus recursos e instituciones. Las principales características de estos modelos son: control local de procesos, la localidad absorbe sus propios beneficios y autonomía en los procesos de desarrollo (Slee, 1994, citado por Bel y Cabaleiro, 2002).

Adicionalmente a los modelos de desarrollo rural endógeno, se debe añadir el concepto de sostenibilidad. La sostenibilidad compuesta por tres factores: ecológico, económico y social (Berga, 1997). Con el componente endógeno y sostenible se logra un escenario donde la comunidad rural puede satisfacer sus necesidades. Además, este debe ir acompañado de actividades empresariales que sean ejecutadas por una sociedad cooperativa (Bel y Cabaleiro, 2002).

De acuerdo a Wossen et al. (2017), las sociedades cooperativas generan cuatro beneficios a sus miembros productores: las cooperativas pueden relajar las restricciones de liquidez otorgando créditos a sus miembros, suministro de información de mercados, mejor precio de mercado a sus productores. La combinación de crédito, información y trabajo de los miembros conlleva a la creación de economía de escalas.

\section{Procedimiento metodológico}

El presente estudio cuenta con un enfoque cuantitativo. Así mismo, el tipo de investigación es aplicada. Por otra parte, el diseño de investigación es de carácter no experimental de tipo transversal. Respecto a la información, la base de datos empleada proviene de los microdatos del Censo Nacional Agropecuario 2014, en Colombia. Dicho censo tuvo una cobertura operativa del $98,9 \%$, donde se incluyen 1.101 municipios, 32 departamentos, 20 áreas no municipalizadas, 773 resguardos indígenas, 181 tierras de comunidades negras y 56 parques nacionales naturales (DANE, 2017). La investigación se limita a los departamentos que conforman la región Caribe.

\subsection{Método de estimación}

Existen dos modelos de elección binaria para este tipo de estudios, que son el modelo Logit y el Probit. Siguiendo a Nugusse et al. (2013), se opta por utilizar el modelo probit porque asume una distribución normal. El modelo probit es utilizado para identificar los factores que impactan significativamente a los productores agrícolas de ñame para asociarse. El modelo posee la siguiente estructura matemática: 


$$
Y_{i}=B_{0}+\sum_{i=1}^{n} B_{i} X_{i}+\varepsilon_{i} \text { donde }_{i} \approx N\left(0, \delta^{2}\right) \mathrm{i}=1,2, \ldots, \mathrm{n}
$$

El vector $X_{i}$ muestra las variables independientes. Como la variable dependiente posee dos opciones de respuesta, se asigna un valor de 1 para aquellas unidades productoras agropecuarias donde el productor agropecuario hace parte de una asociación; y o en caso contrario. Nugusse et al. (2013) muestran que la ecuación (1) se transforma de la siguiente manera:

$$
E\left(Y_{i}=\frac{1}{X_{i}}\right)=B_{0}+\sum_{i=1}^{n} B_{i} X_{i}=\int_{-\infty}^{x_{i}} \Phi(X) d X=\frac{1}{\sqrt{2 \Pi}} \int_{-\infty}^{\infty} e^{-\left(\frac{1}{2}\right) x^{2}} d X
$$

Donde $\Phi(X)$ es la función de distribución acumulada. Los coeficientes que contiene la ecuación 2 son usados para interpretar la dirección. A manera de ejemplo, la probabilidad de que el productor agropecuario se integre a una cooperativa incrementa con $B_{i}$ mayor a o.

$$
\frac{\partial P\left(Y_{i}=\frac{1}{X_{i}}\right)}{\partial X_{i}}=\frac{\partial\left(\frac{Y_{i}}{X_{i} B_{i}}\right)}{\partial X_{i}}=\frac{\partial\left(B_{0}+\sum_{i=1}^{n} B_{i} X_{i}\right)}{\partial X_{i}}
$$

La ecuación 3 se refiere a las elasticidades asociadas al modelo. Es decir, se puede observar cuántas unidades aumenta o disminuye la variable dependiente, respecto a un cambio en una variable independiente, manteniendo las demás variables independientes constantes. La investigación utiliza el efecto marginal de las variables para obtener la magnitud de cada coeficiente.

\subsection{Descripción del modelo}

Las variables se seleccionaron teniendo en cuenta tres criterios:

1. La variable se encuentra referenciada en la literatura analizada.

2. Variables que se encuentran en la literatura, pero se contextualizan a fin de validar su condición en el contexto de la economía del Caribe colombiano.

3. Variables que no se encuentran en la literatura, pero se añaden con el fin de validar su condición en el contexto de estudio.

Adicionalmente, las variables empleadas se pueden construir debido a que la base de datos cuenta con esta información. A continuación, en la Tabla l, se observan las variables empleadas en la construcción del modelo.
El modelo se ejecuta incluyendo la opción de errores estándar robustos para arreglar posibles problemas de heterogeneidad. Posteriormente, se aplica una prueba de multicolinealidad. La forma funcional del modelo es la siguiente:

$$
\begin{aligned}
& \text { prob }\left(\text { Asociarse }=1 \mid X_{i}\right) \\
& \quad B_{0}+B_{1} \text { Crédito }+B_{2} \text { Asistenciatécnica }+B_{3} \\
& \text { Asocomunitarias } \\
& +B_{4} \text { gbovino }+B_{5} \text { cproducida } B_{6} \text { atotal }+ \\
& B_{7} \text { Trabajadoreshogar } \\
& +B_{8} \text { Nproductores }+B_{9} \text { Sirrigación }+ \\
& B_{10} \text { consersuelo } \\
& +B_{11} \text { Fertilizante }+B_{12} \text { Corganico }+ \\
& B_{13} \text { Cquimico }+B_{14} \text { Cbiologico } \\
& +B_{15} \text { Cabastos }+B_{16} \text { Comercializadora }
\end{aligned}
$$

\section{Análisis descriptivo}

Después de depurar los datos, se obtiene información de 27.937 UPA que se distribuyen por departamento de la siguiente manera: Sucre (18,68\%); Córdoba (55,05\%); Bolívar (17,09\%); La Guajira (3,25\%); Atlántico (0,69\%); Magdalena (4,51\%); Cesar (0,57\%); y San Andrés y Providencia $(0,12 \%)$. En la Figura 1, se puede apreciar la distribución por unidades agropecuarias. 


\begin{tabular}{|c|c|}
\hline \multicolumn{2}{|r|}{ Tabla 1. Variables de estudio } \\
\hline Variable dependiente & Descripción \\
\hline Asociarse & $\begin{array}{c}\text { La variable toma el valor de } 1 \text { si el individuo coopera con alguna cooperativa u otro tipo de } \\
\text { organización similar, y toma el valor de o en caso contrario. }\end{array}$ \\
\hline \multicolumn{2}{|r|}{ Variables independientes } \\
\hline \multicolumn{2}{|r|}{ Criterio I } \\
\hline Crédito & $\begin{array}{l}\text { Toma el valor de } 1 \text { si el productor agropecuario ha solicitado crédito en el año de la } \\
\text { encuesta, y o en caso contrario. }\end{array}$ \\
\hline Asistencia técnica & $\begin{array}{l}\text { Toma el valor de } 1 \text { si el productor agropecuario manifiesta que ha recibido asistencia } \\
\text { técnica en sus procesos agropecuarios, y o en caso contrario. }\end{array}$ \\
\hline Asociación comunitaria & $\begin{array}{l}\text { Variable dummie que toma el valor de } 1 \text { si el productor hace parte de una asociación } \\
\text { comunitaria, y o en caso contrario. }\end{array}$ \\
\hline Ganado bovino & Variable continua que muestra el número de cabezas de ganado con que cuenta la UPA. \\
\hline Cantidad obtenida & Variable continua que muestra la cantidad de producción de ñame en toneladas en la UPA. \\
\hline Área total & Variable continua que muestra el número total de hectáreas que conforman la UPA. \\
\hline Trabajo hogar & $\begin{array}{l}\text { Variable continua que muestra el número de familiares del productor que trabajan } \\
\text { dentro de la UPA. }\end{array}$ \\
\hline Sistema de irrigación & $\begin{array}{l}\text { Variable dummie que toma el valor de } 1 \text { si la UPA cuenta con sistema de irrigación de } \\
\text { cultivos y o en caso contrario. }\end{array}$ \\
\hline Uso de fertilizante & Variable dummie que toma el valor de 1 si se aplica fertilizante y o en caso contrario \\
\hline \multicolumn{2}{|r|}{ Criterio 2} \\
\hline \multicolumn{2}{|r|}{ Control de plaguicidas: } \\
\hline Orgánico & $\begin{array}{l}\text { Variable dummie que toma el valor de } 1 \text { si se aplica control orgánico para erradicar plagas } \\
\text { y o en caso contrario. }\end{array}$ \\
\hline Químico & $\begin{array}{l}\text { Variable dummie que toma el valor de } 1 \text { si se aplica control químico para erradicar plagas } \\
\text { y o en caso contrario. }\end{array}$ \\
\hline Biológico & $\begin{array}{l}\text { Variable dummie que toma el valor de } 1 \text { si se aplica control biológico para erradicar } \\
\text { plagas y o en caso contrario. }\end{array}$ \\
\hline \multicolumn{2}{|r|}{ Acceso a mercados } \\
\hline Central de abastos & $\begin{array}{l}\text { Variable dummie que toma el valor de } 1 \text { si comercializa productos en las centrales de } \\
\text { abastos y o en caso contrario. }\end{array}$ \\
\hline Comercializadora & $\begin{array}{l}\text { Variable dummie que toma el valor de } 1 \text { si realiza la venta directa a grupos de } \\
\text { comercializadoras y o en caso contrario. }\end{array}$ \\
\hline
\end{tabular}

\section{Criterio 3}

Técnica de conservación $\quad$ Variable dummie que toma el valor de 1 si la UPA realiza alguna actividad de conserde suelo

vación de suelo, como labranza mínima y siembra directa, y o en caso contrario.

Número de productores Variable continua referente al número de productores que se asociaron para constituir la asociados dentro la UPA UPA.

Fuente: elaboración propia.

Se observa que el $90 \%$ de las UPA se concentran entre los departamentos de Sucre, Córdoba y Bolívar. Lo anterior muestra la importancia socioeconómica que tiene el ñame en estos tres departamentos. Por otro lado, la asociatividad a una cooperativa u otro tipo de organización similar es baja, como se muestra en la Figura 2. En los departamentos de Sucre, Bolívar, La Guajira y Atlántico, más del $10 \%$ de los productores encuestados están asociados a una cooperativa u otro tipo de 
organización similar. Los departamentos de Córdoba, Magdalena y Cesar tienen un porcentaje de asociados menor al $10 \%$.

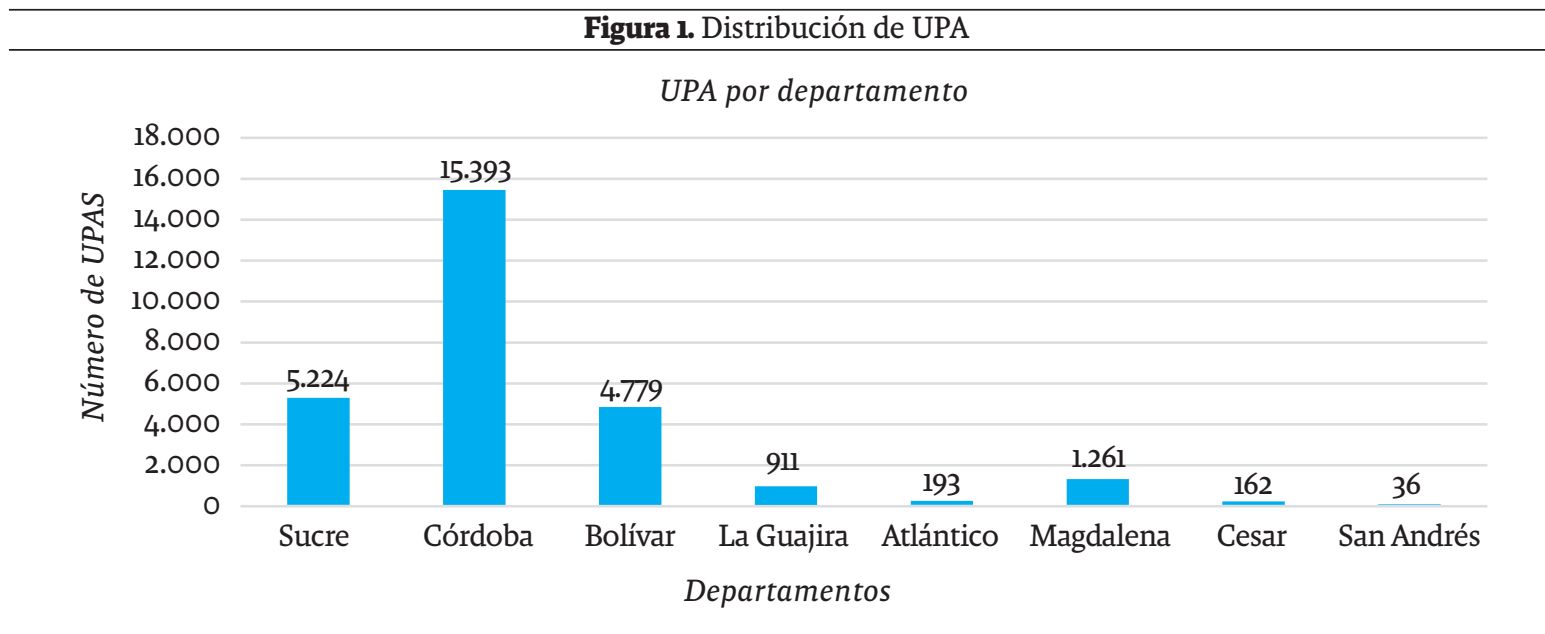

Fuente: elaboración propia basada en datos del Censo Agropecuario 2014 (DANE, 2017).

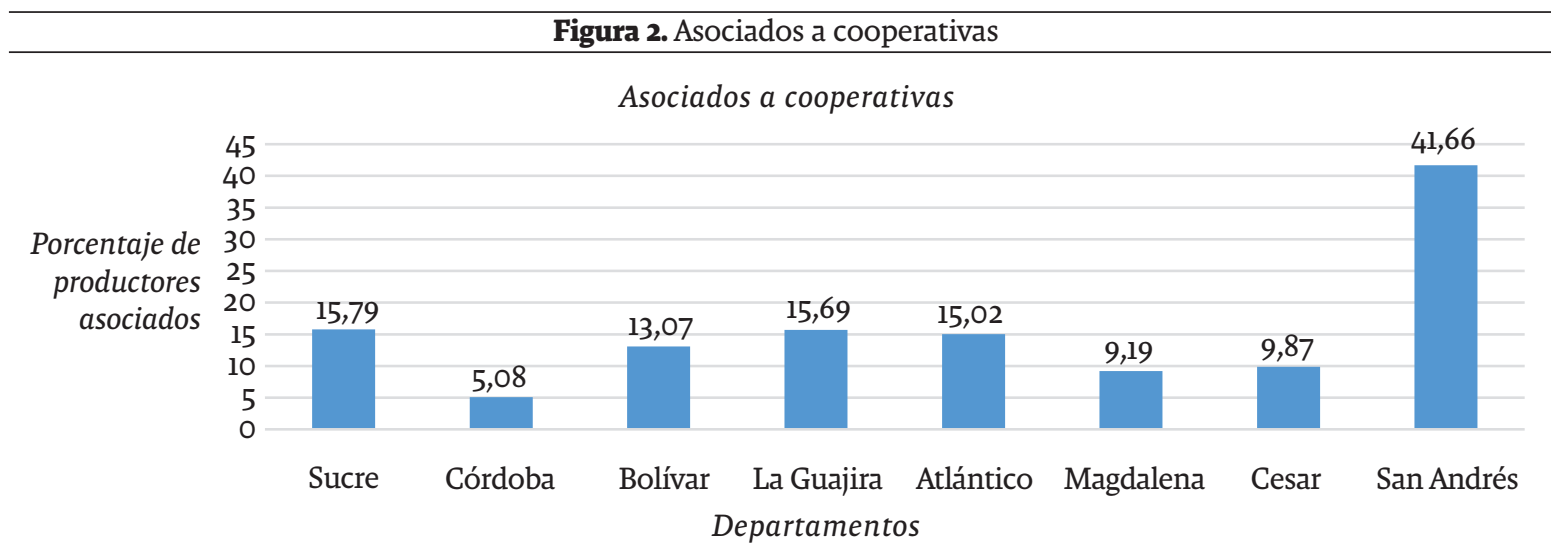

Fuente: elaboración propia basada en datos del Censo Agropecuario 2014 (DANE, 2017).

Así mismo, el departamento de San Andrés cuenta con el mayor porcentaje de asociados a cooperativas con el 41,66\%. Córdoba cuenta con la mayor cantidad de UPA registradas en el estudio, pero con los menores porcentajes de asociados a cooperativas.

\section{Resultados}

La sección de resultados se dividió en dos tipos de análisis: departamental y regional. A continuación, en la Tabla 2, se pueden observar los resultados marginales de las regresiones para cada departamento y para la región Caribe.
Para los departamentos de Cesar y San Andrés y Providencia no fue posible realizar las regresiones, debido a la ausencia de datos en diferentes variables. Los espacios de la Tabla 2 que el software rellenó con 0 se deben a que son variables que presentan problemas de multicolinealidad perfecta; por lo tanto, el software los omite de la regresión. Si dicho valor es mayor a 10 , significa que la variable genera problemas de multicolinealidad aproximada en el modelo (Kutner et al., 2004). En la Tabla Al, se pueden observar los coeficientes del modelo y, en la Tabla A2, la prueba de multicolinealidad realizada. 
Determinantes de la asociación productiva del cultivo de ñame en el caribe colombiano

\begin{tabular}{|c|c|c|c|c|c|c|c|}
\hline Variables & Sucre & Córdoba & Bolívar & La Guajira & Atlántico & Magdalena & Región Caribe \\
\hline \multicolumn{8}{|l|}{ Asociar } \\
\hline \multirow[t]{2}{*}{ Crédito } & $0,043^{* * *}$ & $0,0075^{*}$ & $0,058^{* * *}$ & $-0,04256$ & $0,077^{*}$ & 0,0231 & $0,0217^{\star * *}$ \\
\hline & $-0,01131$ & $-0,004$ & $-0,012$ & $-0,036$ & $-0,042$ & $-0,0325$ & $-0,0042$ \\
\hline \multirow{2}{*}{$\begin{array}{l}\text { Asistencia } \\
\text { técnica }\end{array}$} & $0,2197^{* * *}$ & $0,1237^{* * *}$ & $0,1611^{\star * *}$ & $0,322^{* * *}$ & $0,3311^{* * *}$ & $0,3028^{\star * *}$ & $0,1671^{\star \star *}$ \\
\hline & $-0,1111$ & $-0,0052$ & $-0,0096$ & $-0,0322$ & $-0,05088$ & $-0,0427$ & $-0,0043$ \\
\hline \multirow{2}{*}{$\begin{array}{c}\text { Asociación } \\
\text { comunitaria }\end{array}$} & $-0,2364^{* * *}$ & $-0,0367^{* * *}$ & $-0,2236^{* * *}$ & $-0,5383^{* * *}$ & 0 & 0 & $-0,1692^{* * *}$ \\
\hline & $-0,033$ & $-0,011$ & $-0,031$ & $-0,07$ & (Omitida) & (Omitida) & $-0,01237$ \\
\hline \multirow{2}{*}{$\begin{array}{l}\text { Ganado } \\
\text { bovino }\end{array}$} & $-0,00000093$ & $-0,0001597^{*}$ & 0,00018 & 0,00076 & $0,0025^{*}$ & 0,00029 & $-0,0000322^{* * *}$ \\
\hline & $-0,000083$ & $-0,00009$ & $-0,003982$ & $-0,00048$ & $-0,0013$ & $-0,00033$ & $-0,000000493$ \\
\hline \multirow{2}{*}{$\begin{array}{l}\text { Cantidad } \\
\text { obtenida }\end{array}$} & $0,0042^{* * *}$ & $0,000205^{* * *}$ & 0,000072 & $-0,030^{* * *}$ & 0 & 0,003863 & 0,0000896 \\
\hline & $-0,00109$ & $-0,000054$ & $-0,0013$ & $-0,011$ & (Omitida) & $-0,0023$ & $-0,0001051$ \\
\hline \multirow[t]{2}{*}{ Área total } & $0,00047^{* * *}$ & $-0,000079^{* * *}$ & $-0,0010^{* * *}$ & 0,0000153 & $-0,00016$ & $0,0000141^{* * *}$ & $0,0000245^{* * *}$ \\
\hline & $-0,00005$ & $-0,000012$ & $-0,00026$ & $-0,000017$ & $-0,00075$ & $-0,000000511$ & $-0,00000036$ \\
\hline \multirow{2}{*}{$\begin{array}{c}\text { Productores } \\
\text { de la UPA }\end{array}$} & $-0,00052$ & $0,0070^{* * *}$ & $-0,0092$ & $-0,058^{* *}$ & 0,0097 & $-0,0522498^{* * *}$ & $0,0026^{*}$ \\
\hline & $-0,0024$ & $-0,0022$ & $-0,0099$ & $-0,0288$ & $-0,01897$ & $-0,013$ & $-0,0014$ \\
\hline \multirow{2}{*}{$\begin{array}{c}\text { Sistema de } \\
\text { irrigación }\end{array}$} & $-0,015$ & $0,022^{* \star *}$ & $-0,0419^{\star \star *}$ & 0,026 & $-0,011$ & $-0,02247$ & $-0,0098^{\star * *}$ \\
\hline & $-0,0099$ & $-0,0034$ & $-0,0108$ & $-0,023$ & $-0,03907$ & $-0,0236$ & $-0,0034$ \\
\hline \multirow{2}{*}{$\begin{array}{c}\text { Conservación } \\
\text { de suelo }\end{array}$} & $0,0335^{* * *}$ & $-0,0072^{* *}$ & 0,0098 & 0,018 & $-0,065$ & $-0,055^{* * *}$ & $0,0097^{* \star *}$ \\
\hline & $-0,0089$ & $-0,0302$ & $-0,0092$ & $-0,0254$ & $-0,04$ & $-0,1135$ & $-0,0032$ \\
\hline \multirow[t]{2}{*}{ Fertilizante } & 0,0067 & $0,010^{* * *}$ & $0,028^{* * *}$ & 0,01555 & $-0,00804$ & 0,0075 & $-0,0121^{* * *}$ \\
\hline & $-0,0096$ & $-0,0034$ & $-0,0101$ & $-0,038$ & $-0,04$ & $-0,02122$ & $-0,025$ \\
\hline \multirow{2}{*}{$\begin{array}{c}\text { Trabajo del } \\
\text { hogar }\end{array}$} & $-0,011$ *** & $-0,0013$ & $0,022^{* * *}$ & $-0,05038^{* * *}$ & $-0,0564$ & 0,0009578 & 0,000000546 \\
\hline & $-0,0045$ & $-0,0013$ & $-0,0041$ & $-0,015$ & $-0,04185$ & $-0,0063$ & $-0,0013$ \\
\hline \multicolumn{8}{|c|}{ Uso de plaguicidas } \\
\hline \multirow[t]{2}{*}{ Orgánico } & $0,0342^{* *}$ & $-0,0191^{\star *}$ & 0,019 & $-0,0542$ & 0,1223 & $-0,0824^{*}$ & $0,06591^{* * *}$ \\
\hline & $-0,014$ & $-0,0078$ & $-0,021$ & $-0,066$ & $-0,07609$ & $-0,04605$ & $-0,0055$ \\
\hline \multirow[t]{2}{*}{ Químico } & $-0,0081$ & $-0,012^{\star \star \star}$ & $0,055^{* * *}$ & $0,0815^{* *}$ & $0,1290^{* * *}$ & $-0,20434$ & 0,00047 \\
\hline & $-0,0098$ & $-0,0035$ & $-0,01$ & $-0,041$ & $-0,0451$ & $-0,02168$ & $-0,0035$ \\
\hline \multirow[t]{2}{*}{ Biológico } & $-0,0044$ & $-0,01157$ & 0,06678 & 0,022 & 0 & 0 & $-0,0216$ \\
\hline & $(-0,056)$ & $-0,0278$ & $-0,076$ & $-0,1017$ & (Omitida) & (Omitida) & $-0,02295$ \\
\hline \multicolumn{8}{|c|}{ Acceso a mercado } \\
\hline \multirow{2}{*}{$\begin{array}{c}\text { Central de } \\
\text { abastos }\end{array}$} & $-0,05^{* \star *}$ & 0,011 & $0,022^{*}$ & 0,0231 & $-0,177^{* *}$ & $0,05241^{* \star}$ & $0,021^{\star * *}$ \\
\hline & $-0,01798$ & $-0,0069$ & $-0,011$ & $-0,022$ & $-0,0819$ & $-0,02175$ & $-0,0049$ \\
\hline \multirow{2}{*}{$\begin{array}{c}\text { Comerciali- } \\
\text { zadora }\end{array}$} & $0,0542^{* * *}$ & $-0,021^{* * *}$ & & 0,045 & 0,0244 & & 0,0038256 \\
\hline & $-0,01759$ & $-0,0048$ & & $-0,036$ & $-0,0373$ & & $-0,0058$ \\
\hline $\boldsymbol{N}$ & 5197 & 15186 & 4714 & 907 & 188 & 999 & 27456 \\
\hline
\end{tabular}

Nota: desviación estándar en paréntesis * $\mathrm{p}<0.1 .{ }^{* *} \mathrm{p}<0.05 .{ }^{* * *} \mathrm{p}<0.01$.

Fuente: elaboración propia, utilizando STATA 14, basada en datos del Censo Agropecuario 2014 (DANE, 2017).

\subsection{Análisis departamental}

A continuación, se realiza el análisis de resultados para cada departamento, teniendo en cuenta los criterios en los que fue agrupada cada variable. 


\subsubsection{Criterio 1}

En los resultados arrojados, a nivel departamental, se observa que las razones por las cuales los productores de ñame se asocian varían según el departamento. El acceso a crédito tuvo un efecto positivo y significativo en los departamentos Sucre, Córdoba, Bolívar y Atlántico. Resultados similares fueron encontrados por Ofuoku y Urang (2009) en Nigeria. En el resto de departamentos no fue significativo. Lo anterior es similar al hallazgo que obtuvieron Mensah et al. (2012) en Benín, donde los productores agrícolas no se encontraban interesados en el hecho de obtener créditos comerciales. Estas diferencias pueden ser explicadas debido al hecho de que las asociaciones pueden facilitar el acceso a créditos en algunos departamentos, mientras que en otros no.

La asistencia técnica fue positiva y significativa en todos los departamentos, resultados consistentes con los encontrados en estudios realizados en Nigeria, Etiopia y Suazilandia (Mabuza et al., 2015; Munasib y Jordan, 2011; Ofuoku y Urang, 2009). Lo anterior se debe a que los productores reconocen que asociarse facilita la transferencia de nuevos conocimientos acerca de su actividad productiva, experiencias que son consideradas para el desarrollo futuro de los cultivadores.

Por otra parte, la variable "asociaciones comunitarias" tiene un efecto negativo y significativo en los departamentos de Sucre, Córdoba, Bolívar y La Guajira. Esto puede deberse a que los productores prefieren unirse a grupos informales en vez de a las cooperativas. Según Szalbocs et al. (2016), este tipo de asociaciones informales deben formalizarse por medio de cooperativas. La variable "ganado bovino" se mostró significativa y positiva, al $10 \%$, en el departamento del Atlántico, aunque las variaciones porcentuales son menores al 0,3\%. Claramente, este efecto podría omitirse. En el resto de departamentos no fue significativa. Lo anterior es un resultado contrario al obtenido por Abate et al. (2014). Esto puede deberse a que aquellos productores de ñame que también realizan la actividad ganadera poseen mayor facilidad para la obtención de recursos, porque pueden utilizar las ganancias de esta actividad para financiarse. Por ende, deciden no participar en la acción colectiva formal.
La cantidad obtenida durante el año fue significativa y positiva en los departamentos de Sucre y Córdoba al $1 \%$, aunque los efectos marginales son menores al 0,5\%. En el departamento de La Guajira, la variable fue significativa y negativa al $1 \%$; y su efecto marginal fue de $3 \%$. En el resto de departamentos no se observa significancia. Por lo tanto, la variable se considera como no relevante. Lo anterior es un resultado contrario a lo encontrado en Etiopia y China, donde exponen que la cantidad obtenida tiene un impacto positivo en la membresía a cooperativas, siempre y cuando el cultivo sea de tipo comercial (Abate et al., 2014; Zheng et al., 2012). Entonces, la no significancia puede mostrar que el cultivo de ñame podría estar más relacionado con un cultivo de subsistencia.

El área total de la UPA fue positiva y significativa al $1 \%$ en Sucre y Magdalena. Estos resultados son similares a estudios hechos en Nigeria y Etiopía (Abate et al., 2014; Agbonlahor et al., 2012; Ma y Abdulai, 2016). Aquellos productores de ñame que cuentan con menos áreas cultivables pueden asociarse para poder acceder a más extensión de terreno. En Córdoba y Bolívar tuvo un efecto negativo y significativo, del mismo modo, cuando el productor agropecuario posee una mayor extensión de terreno puede cultivar más y acceder a recursos causando que no sea necesario hacer parte de la asociación (Francesconi y Heerink, 2010; Ito et al., 2012; Mensah et al., 2012).

La variable "sistema de irrigación" fue significativa y positiva en Córdoba. En el departamento de Bolívar, fue significativa y negativa. En el resto de departamentos no fue significativa; resultado similar encuentra Abate et al. (2014). Esto puede deberse a que los productores son indiferentes a la asociación productiva para poder acceder a un sistema de irrigación. El número de miembros del hogar que trabaja dentro de la UPA fue positivo y significativo en Bolívar; se observa que este hallazgo es similar a lo encontrado por Verhofstadt y Maertens (2015). Esto puede deberse a que los productores de ñame en este departamento requieren de la mano de obra familiar para realizar sus actividades. Por lo tanto, pueden ver las cooperativas como un medio donde acceden a mano de obra. En el resto de departamentos no fue significativo. 
La variable "fertilizante" fue significativa en los departamentos de Córdoba y Bolívar. Lo anterior es un hallazgo a favor de lo expuesto por Ofuoku y Urang (2009), donde la asociación productiva puede facilitar el acceso a insumos. En los departamentos donde no fue significativo, puede deberse a que acceden a estos insumos sin ninguna restricción.

\subsubsection{Criterio 2}

Se optó por identificar los efectos de los diferentes tipos de controles de plaga sobre la asociación. Por lo tanto, la variable fue dividida en tres diferentes variables. El control de plagas de tipo orgánico fue significativo y positivo en el departamento de Sucre. En Córdoba y Magdalena, la variable fue significativa y negativa. En el resto de departamentos, no fue significativo.

El control de tipo químico fue positivo y significativo en los departamentos de Bolívar, La Guajira y el Atlántico. En Córdoba, la variable fue significativa y negativa. En el resto de departamentos, no tuvo efecto. El control biológico no fue significativo en ninguno de los departamentos. Se observa que, en la mayoría de departamentos, el utilizar algún tipo de fertilizantes, especialmente los de tipo químico, aumenta la propensión a asociarse. Hallazgo similar encuentran Ofuoku y Urang (2009) allí donde productores agrícolas están motivados a asociarse a cooperativas, porque pueden acceder a insumos. Por otra parte, las alternativas biológicas y orgánicas son poco significativas. Resultado contrario a lo encontrado por Munasib y Jordan (2011), donde manifiestan que el asociarse aumenta la probabilidad de utilizar algún tipo de control de plaga.

La variable acceso a mercados, como comúnmente aparece en la literatura, fue dividida en dos variables: venta a comercializadora y venta a central de abastos. La venta directa a central de abastos fue positiva y significativa en Bolívar y Magdalena. En Córdoba y La Guajira, no tuvo efecto significativo. En el Atlántico y Sucre, tuvo un efecto significativo y negativo. Se observa que algunos departamentos encuentran en las cooperativas beneficios que les permiten penetrar los mercados en las centrales de abastos.
La variable "venta de producto" a comercializadora fue significativa y positiva en Sucre. Lo anterior se puede deber a que, en el departamento de Sucre, la asociación productiva aumenta el poder de negociación. En los departamentos donde el efecto es no significativo, se presentan cambios marginales bajos que se pueden ignorar. Esto puede deberse a que no consideran la asociación productiva como una forma de penetrar mercados conformados por grandes comercializadoras y prefieren alternativas como las centrales de abastos, debido a que las primeras pueden ser más exigentes con la calidad del producto que necesitan.

De forma general, según Lazíková et al. (2014), la asociación productiva facilita el acceso a mercados. Esto se puede corroborar en la variable "central de abastos". En aquellos departamentos donde se obtienen efectos no significativos, o significativos, pero negativos, es porque los productores realizan la comercialización de forma independiente (Nugusse et al., 2013).

\subsubsection{Criterio 3}

Por otra parte, se analiza el grupo de variables del tercer criterio. La variable "número de productores asociados dentro de la UPA" fue significativa y positiva en Córdoba. Esto puede deberse a que los pequeños productores deciden juntarse para conformar una UPA, y así poder desarrollar sus actividades agropecuarias. Además, las cooperativas son una forma en la que se pueden explotar economías de escala. En la Guajira y el Magdalena fue significativo y negativo. Es posible que no consideren relevante juntarse a una cooperativa, y prefieran asociarse con productores agropecuarios y realizar sus actividades de manera aislada. Por último, la variable de uso de técnica de conservación de suelo, en los departamentos en donde es significativa y no significativa, posee un efecto marginal bajo que se podría considerar despreciable. Lo anterior muestra que el uso de técnicas como siembra directa o labranza mínima son empleadas tanto por los productores asociados como por los no asociados, causando que sea poco relevante al momento de asociarse. 


\subsection{Análisis regional}

A continuación, se realiza el análisis de resultados utilizando un modelo econométrico para la región Caribe, teniendo en cuenta los criterios en los que fue agrupada cada variable.

\subsubsection{Criterio 1}

Con el fin de observar los efectos agregados de los departamentos, se opta por realizar una regresión regional. A continuación, se analizan las variables que integran el primer criterio. La variable "crédito" se mostró significativa y positiva. Este resultado muestra que aquellos productores de ñame que han tenido crédito consideran que las cooperativas son un canal por el cual pueden obtener financiamiento (Nugusse et al., 2013; Ofuoku y Urang, 2009). La asistencia técnica se mostró significativa y positiva, debido a que los productores agrícolas consideran necesario mantenerse actualizados respecto a sus actividades agrícolas (Mabuza et al., 2015; Nugusse et al., 2013; Ofuoku y Urang, 2009).

La asociación comunitaria se mostró significativa y negativa. Estos resultados son contrarios a los identificados por Koutsou et al. (2014), donde la asociación informal mejoraba la cohesión y la participación en cooperativas. Según Szalbocs et al. (2016) las asociaciones informales se deben transformar en formales por medio de las cooperativas. La variable "ganado bovino" es significativa y positiva, aunque el valor marginal es mínimo. En el análisis departamental, esta variable se mostró no significativa en la mayoría de los departamentos. Este resultado es similar al encontrado por Abate et al. (2014), donde los productores pueden recibir beneficios de actividades agropecuarias.

La cantidad obtenida no es significativa, resultado contrario a lo identificado por Zheng et al. (2012). Lo anterior puede deberse a que, a nivel regional, el cultivo no es de tipo comercial y no desean unirse a cooperativas. El área total es positiva y significativa, aunque se debe considerar que, en los estudios revisados, esta variable tiene un comportamiento de tipo cóncavo. Es decir, a medida que la cantidad de tierra se acerca a un umbral máximo, la probabilidad de asociarse disminuye gradualmente, hasta el punto en que se convierte en negativa (Abate et al., 2014; Francesconi y Heerink, 2010; Mensah et al.,
2012; Zheng et al., 2012). Se intentó añadir la variable "área al cuadrado" para analizar la concavidad, pero no fue posible porque la multicolinealidad aproximada de dicha variable era superior a 10.

El sistema de irrigación es negativo y significativo, aunque su valor marginal es reducido, es decir, cerca del 1\%. Abate et al. (2014) encuentra esta variable no significativa en su estudio. La significancia en el estudio puede deberse al hecho de que, en las cooperativas, encuentran recursos que les permiten obtener sistemas de irrigación. La variable "fertilizante" es negativa y significativa, resultado contrario a lo encontrado por Ofuoku y Urang (2009). Es posible que, a nivel general, aquellos que usan fertilizantes los consigan por otras fuentes, sin tener que depender de cooperativas.

\subsubsection{Criterio 2}

El plaguicida orgánico es significativo y positivo. Este resultado está a favor de lo encontrado por Munasib y Jordan (2011), donde asociarse permite que se tome control de plagas de tipo ambiental. El plaguicida de tipo químico fue no significativo, igual que el de tipo biológico. A pesar de que solo la variable de tipo orgánico se mostró significativa, existen intereses por pertenecer a cooperativas para acceder a insumos. Resultados similares a los encontrados por Ofuoku y Urang (2009).

La variable "venta central de abastos" se mostró significativa y positiva. La variable "ventas comercializadora" se mostró como no significativa. Lo anterior puede deberse a que, aquellos que venden sus productos en las centrales de abastos, no necesitan tantos controles como en las grandes comercializadoras. Lo anterior es similar a lo encontrado por Nugusse et al. (2013), que manifiestan que los productores utilizan las cooperativas para acceder más fácil a los mercados.

\subsubsection{Criterio 3}

La variable "técnica de conservación de suelo" se mostró como significativa y positiva, aunque su efecto es reducido. Este resultado es de esperarse porque las cooperativas generan conciencia ambiental. Por otra parte, el hecho de conformar una UPA con otros productores aumenta la probabilidad de asociarse. Esto se puede explicar porque el 
productor es beneficiado por las economías de escala, obtenidas por agruparse de manera independiente, formalmente, $y$ por asociarse a cooperativas.

\section{Conclusiones}

La investigación muestra que las variables que influencian la probabilidad de vincularse a una asociación productiva a nivel regional son el acceso al crédito, la asistencia técnica, pertenecer a alguna asociación comunitaria, las unidades de ganado bovino dentro de la UPA, el área de la UPA, el número de productores que conforman la UPA, el uso de fertilizantes orgánicos y la venta a la central de abastos. Los resultados siguen los aportes teóricos planteados acerca de la asociación productiva. Se evidencia claramente que los productores agrícolas de ñame, tanto pequeños como medianos y grandes, persiguen fuentes de financiamiento, acceso a la información, poder de mercado y acceso a insumos.

Se observa que las asociaciones productivas pretenden que los productores realicen sus actividades económicas sin afectar el medio ambiente. Del mismo modo, la asociación productiva disminuye la brecha entre los grandes productores y los pequeños, debido a que la acción colectiva permite el acceso a recursos que, de manera individual, el pequeño productor no podría alcanzar. Además, la asociación productiva permite prácticas agrícolas correctas como controles orgánicos y biológicos que poseen un valor agregado más alto, debido a que el producto presentará poco o ningún agente químico nocivo para la salud y, por ende, el cultivo deja de ser de tipo "subsistencia" para convertirse en "comercial".

Aunque en la mayoría de los estudios la asociación comunitaria tiene efectos positivos, en este se encontró una connotación negativa, puesto que el hecho de pertenecer a una asociación comunitaria no motiva a hacer parte de una asociación formal. Es indispensable mostrar a los productores que, así como consideran importante asociarse con otros miembros de su comunidad, también es necesario que construyan relaciones formales horizontales, dentro de las cooperativas, que permitan mejorar su productividad. De forma general, la asociación productiva debe ser vista en el Caribe colombiano como una forma mancomunada de cooperación entre los productores, el sector privado y el público, contribuyendo así al aumento del bienestar y la producción agrícola.

\section{Recomendaciones}

La asociación productiva puede ser vista como un motor de emprendimiento en la región, debido a que permite el control local de procesos, la retención de beneficios y la realización local de los procesos de desarrollo. La retención de beneficios se observa en la obtención de recursos como la información y el financiamiento, e insumos de los que anteriormente no disponían. Se recomienda que el Estado, junto con los productores y el sector privado, empleen la asociación productiva como un medio por el cual se puedan ofrecer fuentes de financiamiento. El sector privado podría encontrar fuentes de inversión dentro de las estructuras de asociación productiva, por medio de la construcción de asociaciones de pequeños productores, que ofrecerían un producto de calidad para comercializarse en el exterior.

Así mismo, la asistencia técnica es un incentivo indispensable para asociarse. Por lo tanto, se recomienda que instituciones, como el Servicio Nacional de Aprendizaje (SENA), utilicen la asociación productiva como un medio por el cual los productores de ñame obtengan información acerca de las necesidades del mercado y las nuevas tecnologías empleadas en el cultivo. Dentro de esta información, se debe enfatizar la importancia que tiene el cultivo tanto en la alimentación como en los derivados obtenidos en la industria farmacéutica. Por otro lado, es necesario que, dentro de las asociaciones productivas, se promueva la importancia que posee el uso de insumos de mínimo o nulo impacto ambiental.

Por último, el Estado debe velar por que las asociaciones productivas contribuyan a aumentar el poder de negociación, debido a que esto motivará a que los pequeños y medianos productores aumenten su motivación para asociarse, contribuyendo al aumento del desarrollo económico de su región. Además, las asociaciones productivas podrían estructurarse de tal manera que los cooperados puedan contratar mano de obra, con el fin de que no se encuentren restringidos a utilizar la mano de obra familiar. De esta manera, se evita que empleen a niños menores de edad, como se detectó en algunos casos. 
Henry Mendoza-Crespo • Mauricio Ortiz-Velásquez

\section{Anexo}

Tabla Al. Coeficientes de los modelos probit por departamento y región ejecutados con errores estándar robustos (VCE)

\begin{tabular}{|c|c|c|c|c|c|c|c|}
\hline Variables & Sucre & Córdoba & Bolívar & La Guajira & Atlántico & Magdalena & Región Caribe \\
\hline \multicolumn{8}{|l|}{ Asociar } \\
\hline \multirow[t]{2}{*}{ Crédito } & $0,2516^{* * *}$ & $0,089^{*}$ & $0,31^{* * *}$ & $-0,25$ & $0,65^{*}$ & 0,1382 & $0,1542^{* \star *}$ \\
\hline & $-0,064$ & $-0,048$ & $-0,068$ & $-0,21$ & $-0,34$ & $-0,1947$ & $-0,029$ \\
\hline \multirow{2}{*}{$\begin{array}{l}\text { Asistencia } \\
\text { técnica }\end{array}$} & $1,25^{* * *}$ & $1,479^{\star \star *}$ & $0,88^{* * *}$ & $1,90^{* * *}$ & $2,77^{* * *}$ & $1,81^{* * *}$ & $1,1851^{\star \star \star}$ \\
\hline & $-0,07$ & $-0,05$ & $-0,055$ & $-0,21$ & $-0,4825$ & $-0,2627$ & $-0,031$ \\
\hline \multirow{2}{*}{$\begin{array}{l}\text { Asociación } \\
\text { comunitaria }\end{array}$} & $-1,35^{* * *}$ & $-0,4359^{* \star *}$ & $-1,22^{* * *}$ & $-3,1759^{\star * *}$ & 0 & 0 & $-1,19^{* * *}$ \\
\hline & $-0,196$ & $-0,1375$ & $-0,17$ & $-0,44$ & (Omitida) & (Omitida) & $-0,089$ \\
\hline \multirow{2}{*}{$\begin{array}{l}\text { Ganado } \\
\text { bovino }\end{array}$} & $-0,00053$ & $-0,0001597^{*}$ & 0,001025 & 0,0044 & $0,021^{*}$ & 0,0017 & $-0,00022^{* * *}$ \\
\hline & $-0,00047$ & $-0,00009$ & $-0,02$ & $-0,002$ & $-0,11$ & $-0,002$ & $-0,000345$ \\
\hline \multirow{2}{*}{$\begin{array}{l}\text { Cantidad } \\
\text { obtenida }\end{array}$} & $0,0242^{* * *}$ & $-0,0023^{* \star *}$ & 0,00039 & $-0,18^{* \star *}$ & 0 & 0,023 & 0,0006352 \\
\hline & $-0,0062$ & $-0,00064$ & $-0,007$ & $-0,069$ & (Omitida) & $-0,014$ & $-0,00744$ \\
\hline \multirow[t]{2}{*}{ Área total } & $0,0026^{* * *}$ & $-0,0009479^{\star \star *}$ & $-0,0059^{* * *}$ & 0,0000904 & $-0,0013$ & $0,000084^{* * *}$ & $0,00017245^{* * *}$ \\
\hline & $-0,0029$ & $-0,00014$ & $-0,0014$ & $-0,0001$ & $-0,0062$ & $-0,000043$ & $-0,000023$ \\
\hline \multirow{2}{*}{$\begin{array}{c}\text { Productores } \\
\text { de la UPA }\end{array}$} & $-0,0029$ & $0,083^{* * *}$ & $-0,05$ & $-0,3468^{\star *}$ & 0,082 & $-0,3121^{* * *}$ & $0,018^{*}$ \\
\hline & $-0,013$ & $-0,026$ & $-0,054$ & $-0,1698$ & $-0,1595$ & $-0,079$ & $-0,063$ \\
\hline \multirow{2}{*}{$\begin{array}{c}\text { Sistema de } \\
\text { irrigación }\end{array}$} & $(-0,086)$ & $0,2637^{* * *}$ & $-0,22^{* \star *}$ & 0,1534 & $-0,09$ & $-0,1344$ & $-0,070^{* * *}$ \\
\hline & $-0,057$ & $-0,039$ & $-0,06$ & $-0,14$ & $-0,32$ & $-0,1418$ & $-0,024$ \\
\hline \multirow{2}{*}{$\begin{array}{c}\text { Conservación } \\
\text { de suelo }\end{array}$} & $-0,192^{* * *}$ & $-0,0858^{* *}$ & 0,053 & 0,11 & $-0,54$ & $-0,333^{* * *}$ & $0,0612^{* * *}$ \\
\hline & $-0,051$ & $-0,039$ & $-0,05$ & $-0,1531$ & $-0,3452$ & $-0,1135$ & $-0,022$ \\
\hline \multirow[t]{2}{*}{ Fertilizante } & 0,038 & $0,1230 * * *$ & $0,1544^{* * *}$ & 0,0917 & $-0,067$ & 0,045 & $-0,085^{* * *}$ \\
\hline & $-0,055$ & $-0,04$ & $-0,05$ & $-0,2284$ & $-0,34$ & $-0,1269$ & $-0,025$ \\
\hline \multirow{2}{*}{$\begin{array}{c}\text { Trabajo del } \\
\text { hogar }\end{array}$} & $-0,06^{* * *}$ & $-0,015$ & $0,122^{* * *}$ & $-0,2972^{\star \star \star}$ & $-0,4734$ & 0,00578 & 0,0000387 \\
\hline & $-0,026$ & $-0,0162$ & $-0,02$ & $-0,092$ & $-0,3463$ & $-0,037$ & $-0,0093$ \\
\hline \multicolumn{8}{|c|}{ Uso de plaguicidas } \\
\hline \multirow[t]{2}{*}{ Orgánico } & $0,1964^{* *}$ & $-0,22^{* *}$ & 0,1083 & $-0,32$ & 1,02 & $-0,4934^{*}$ & $0,463^{* * *}$ \\
\hline & $-0,085$ & $-0,0931$ & $-0,11$ & $-0,3965$ & $-0,6505$ & $-0,2698$ & $-0,039$ \\
\hline \multirow[t]{2}{*}{ Químico } & $-0,046$ & $-0,1415^{* * *}$ & $0,3023^{* * *}$ & $0,4813^{* *}$ & $1,08^{\star * *}$ & $-0,1222$ & 0,0033 \\
\hline & $-0,05$ & $-0,042$ & $-0,05$ & $-0,2441$ & $-0,35$ & $-0,1292$ & $-0,025$ \\
\hline \multirow[t]{2}{*}{ Biológico } & $-0,025$ & $-0,1375$ & 0,366 & 0,1325 & 0 & 0 & $-0,1531$ \\
\hline & $(-0,32)$ & $-0,33$ & $-0,4172$ & $-0,22$ & (Omitida) & (Omitida) & $-0,1627$ \\
\hline \multicolumn{8}{|c|}{ Acceso a mercado } \\
\hline \multirow{2}{*}{$\begin{array}{c}\text { Central de } \\
\text { abastos }\end{array}$} & $-0,29^{\star \star \star}$ & 0,1347 & $0,123^{*}$ & 0,1368 & $-1,49^{* *}$ & $0,3135^{\star *}$ & $0,1505^{* * *}$ \\
\hline & $-0,1$ & $-0,082$ & $-0,064$ & $-0,1322$ & $-0,6701$ & $-0,1281$ & $-0,034$ \\
\hline \multirow{2}{*}{$\begin{array}{c}\text { Comerciali- } \\
\text { zadora }\end{array}$} & $0,3112^{* \star *}$ & $-0,2542^{\star \star \star}$ & & 0,2965 & 0,2053 & & 0,027 \\
\hline & $-0,1$ & $-0,056$ & & $-0,092$ & $-0,3183$ & & $-0,041$ \\
\hline $\boldsymbol{N}$ & 5197 & 15186 & 4714 & 907 & 188 & 999 & 27456 \\
\hline
\end{tabular}

Nota: desviación estándar en paréntesis * $\mathrm{p}<0.1$ $^{* *} \mathrm{p}<0.05 .{ }^{* *} \mathrm{p}<0.01$.

Fuente: elaboración propia, utilizando STATA 14, basada en datos del Censo Agropecuario 2014 (DANE, 2017). 


\begin{tabular}{|c|c|c|c|c|c|c|c|c|c|c|c|c|c|c|}
\hline \multirow[t]{2}{*}{ Variables } & \multicolumn{2}{|c|}{ Sucre } & \multicolumn{2}{|c|}{ Córdoba } & \multicolumn{2}{|c|}{ Bolívar } & \multicolumn{2}{|c|}{ La Guajira } & \multicolumn{2}{|c|}{ Atlántico } & \multicolumn{2}{|c|}{ Magdalena } & \multicolumn{2}{|c|}{ Regional } \\
\hline & VIF & 1/VIF & VIF & $1 /$ VIF & VIF & $1 / \mathrm{VIF}$ & VIF & $1 / \mathrm{VIF}$ & VIF & $1 / \mathrm{VIF}$ & VIF & $1 / \mathrm{VIF}$ & VIF & $1 / \mathrm{VIF}$ \\
\hline Crédito & 1,24 & 0,8041 & 1,25 & 0,8 & 1,21 & 0,82645 & 1,43 & 0,699301 & 1,45 & 0,68966 & 1,14 & 0,877193 & 1,21 & 0,82645 \\
\hline Asistencia técnica & 1,21 & 0,8259 & 1,07 & 0,935 & 1,43 & 0,6993 & 1,77 & 0,564972 & 1,26 & 0,79365 & 1,1 & 0,909091 & 1,17 & 0,8547 \\
\hline Asociación comunitaria & 1,13 & 0,8847 & 1,34 & 0,746 & 1,13 & 0,88496 & 2,01 & 0,497512 & & & & & 1,19 & 0,84034 \\
\hline Ganado bovino & 3,88 & 0,2578 & 1,75 & 0,571 & 1,23 & 0,81301 & 1,14 & 0,877193 & 1,42 & 0,70423 & 1,39 & 0,719425 & 1,3 & 0,76923 \\
\hline Cantidad obtenida & 1,18 & 0,8481 & 1,03 & 0,971 & 1,04 & 0,96154 & 1,09 & 0,917431 & & & 1,28 & 0,78125 & 1,03 & 0,97087 \\
\hline Área total & 4,18 & 0,2393 & 2,6 & 0,385 & 1,44 & 0,69444 & 1,29 & 0,775194 & 1,07 & 0,93458 & 1,24 & 0,806452 & 1,37 & 0,72993 \\
\hline Productores de la UPA & 2,06 & 0,4865 & 4,62 & 0,216 & 4,04 & 0,24752 & 4,85 & 0,206186 & 3,13 & 0,31949 & 1,86 & 0,537634 & 2,93 & 0,3413 \\
\hline Sistema de irrigación & 3,81 & 0,2624 & 2,67 & 0,375 & 3,16 & 0,31646 & 3,57 & 0,280112 & 1,45 & 0,68966 & 3,78 & 0,26455 & 2,81 & 0,35587 \\
\hline Conservación de suelo & 2,04 & 0,49 & 2,01 & 0,498 & 2,26 & 0,44248 & 1,82 & 0,549451 & 2,14 & 0,46729 & 2,91 & 0,343643 & 1,99 & 0,50251 \\
\hline Fertilizante & 2,33 & 0,4292 & 2,84 & 0,352 & 1,74 & 0,57471 & 2,21 & 0,452489 & 2,69 & 0,37175 & 3,01 & 0,332226 & 2,32 & 0,43103 \\
\hline Trabajo del hogar & 1,65 & 0,6047 & 2,01 & 0,498 & 1,55 & 0,64516 & 2,36 & 0,423729 & 1,23 & 0,81301 & 1,71 & 0,584795 & 1,64 & 0,60976 \\
\hline \multicolumn{15}{|l|}{ Uso de plaguicidas } \\
\hline Orgánico & 1,87 & 0,5347 & 1,2 & 0,833 & 1,16 & 0,86207 & 1,53 & 0,653595 & 1,25 & 0,8 & 1,14 & 0,877193 & 1,21 & 0,82645 \\
\hline Químico & 2,8 & 0,3566 & 3,1 & 0,323 & 2,47 & 0,40486 & 1,54 & 0,649351 & 2,19 & 0,45662 & 3,46 & 0,289017 & 2,82 & 0,35461 \\
\hline Biológico & 1,01 & 0,991 & 1,01 & 0,99 & 1,01 & 0,9901 & 1,02 & 0,980392 & & & & & 1,03 & 0,97087 \\
\hline \multicolumn{15}{|l|}{ Acceso a mercado } \\
\hline Central de abastos & 1,27 & 0,786 & 1,42 & 0,704 & 1,74 & 0,57471 & 2,27 & 0,440529 & 2,39 & 0,41841 & 2,48 & 0,403226 & 1,33 & 0,75188 \\
\hline Comercializadora & 6,39 & 0,1564 & 5,83 & 0,172 & & & 5,41 & 0,184843 & 1,22 & 0,81967 & & & 5,64 & 0,1773 \\
\hline
\end{tabular}

Fuente: elaboración propia, utilizando STATA 14, basada en datos del Censo Agropecuario 2014 (DANE, 2017).

\section{Referencias}

Abate, G. T., Francesconi, G. N. y Getnet, K. (2014). Impact of agricultural cooperatives on smallholders' technical efficiency: empirical evidence from Ethiopia. Annals of Public \& Cooperative Economics, 85(2), 257-286. https://doi.org/10.1111/apce.12035

Acevedo, M. A., Salcedo, M. J. y Sandoval, A. I. (2015). Desarrollo y productividad del ñame (Dioscorea trífida y Dioscoreaesculenta) en diferentes condiciones hídricas. Acta Agronómica, 64(1), 30-35. https://doi.org/10.15446/acag.v64n1.43917

Agbonlahor, M. U., Enilolobo, O. S., Sodiaya, C. I., Akerele, O. y Oke, J. T. (2012). Accelerating rural growth through collective action: groups' activities and determinants of participation in southwestern Nigeria. Journal of Rural Social Sciences, 27(1), 114-136.

Alesina, A. y La Ferrara, A. (2000). Determinants of trust. Working Paper 7621. National Burau of Economics Research.

Álvarez, A. (2000). Prácticas agronómicas para el cultivo del ñame. En M. Guzmán y G. Buitrago (Eds.), Ñame: producción de semilla por biotecnología (pp. 55-65). Unibiblos.

Amusa, N., Adegbite, A., Muhammed, S. y Baiyewu, R. (2003). Yam disease and its management in Nigeria. African Journals of Biotecnology, 2(12), 497-502. https://doi.org/10.5897/AJB2003.000-1099

Arrieta, L., Chamorro, L. y Montes, D. (2017). Actividad antimicrobiana de bacterias endófitas aisladas de orégano serrano (Lippiaoriganoides) contra Burkholderiaglumae y Colletotrichumgloeosporioides. Revista Colombiana de Ciencia Animal - RECIA, 9(S), 93-98. https://doi.org/10.24188/recia. v9.nS.2017.526 
Bel, P. y Cabaleiro, M. (2002). La sociedad cooperativa: fórmula idónea para el desarrollo rural endógeno y sostenible. Estudios Agro sociales y Pesqueros, (194), 9-25.

Berga, A. (1997). Sistemas rurales y desarrollo sostenible. Revista de desarrollo rural y cooperativismo agrario, (1), 9-22.

Borges, M., Batista R., Meneses, S., Gómez, R., Malaurie, B., Hamon, P. y Demenorval, C. L. (2011). Optimización de un medio de cultivo para plantas micropropagadas de Dioscoreaalata L. Revista Colombiana de Biotecnología, 13(2), 221-228. https://doi.org/10.15446/rev.colomb.biote

Bourdieu, P. (1986). The forms of capital. En J. Richardson (Ed.), Handbook of Theory and Research for the Sociology of Education (pp. 241-258). Greenwood Press.

Cechin, A., Bijman, J., Pascucci, S. y Omta, O. (2013). Decomposing the Member Relationship in Agricultural Cooperatives: Implications for Commitment. Agribusiness, 29(1), 39-61. https://doi. org/10.1002/agr.21321

Cerón, L., Higuera, B., Sánchez, J., Bustamante, S. y Gustavo, B. (2006). Crecimiento y desarrollo de Colletotrichumgloeosporioides f. alatae durante su cultivo en medios líquidos. Acta Biológica Colombiana, 11(1), 99-109.

Coleman, J. (1990). Foundations of social theory. Belknap Press.

DANE -Departamento Administrativo Nacional de Estadística-. (2017). Censo Nacional Agropecuario 2014. https://www.dane.gov.co/index.php/estadisticas-por-tema/agropecuario/ censo-nacional-agropecuario-2014

Doncel, P. y Pérez, A. (2017). Burkholderiacepacia aisladas de variedades de ñame con actividad antimicrobiana contra Colletotrichumgloeosporioides. Revista Colombiana de Ciencia Animal RECIA, 9(S), 31-38. https://doi.org/10.24188/recia.v9.nS.2017.518

Francesconi, G. y Heerink, N. (2010). Ethiopian Agricultural Cooperatives in an Era of Global Commodity Exchange: Does Organizational Form Matter? Journal of African Economies, 20(1), 153177. https://doi.org/10.1093/jae/ejq036

Glaeser, E., Laibson, D. y Sacerdote, B. (2002). An economic approach to social capital. Economic Journal, 112(483), 437-458. http://dx.doi.org/10.2139/ssrn.263420

González, M. (2012). El Ñame (Dioscoreaspp.). Características, usos y valor medicinal. Aspectos de importancia en el desarrollo de su cultivo. Cultivos Tropicales, 33(4), 5-15.

Green, K., Abang, M. y Lloba, C. (2000). A rapid Bioassay for Screening Yam Germplasm for Response to Anthracnose. Tropical Science, (40), 132-138.

Hata, Y., Reguero, M., Arteaga, L., Buitrago, G. y Álvarez, A. (2003). Evaluación del contenido de sapogeninas en variedades nativas de ñame (Dioscoreaspp.), provenientes de la colección de la Universidad de Córdoba. Revista Colombiana de Ciencia Química Farmacéutica, 32(2), 149-157. https://doi.org/10.15446/rcciquifa

Ito, J., Bao, Z. y Su, Q. (2012). Distributional effects of agricultural cooperatives in China: Exclusion of smallholders and potential gains on participation. Food Policy, 37(6), 700-709. https://doi. org/10.1016/j.foodpol.2012.07.009 
Koutsou, S., Partalidou, M. y Ragkos, A. (2014). Young farmers' social capital in Greece: Trust levels and collective actions. Journal of Rural Studies, 34, 204-211. https://doi.org/10.1016/j.jrurstud.2014.02.002

Kutner, M. H., Nachtsheim, C. J. y Neter, J. (2004). Applied Linear Regression Models. McGraw-Hill Irwin.

Lazíková, U., Bartová, L., Škriniarová, K. y Bandlerová, A. (2014). Association of the agricultural cooperatives into producer groups. Journal of Central European Green Innovation, 2(4), 1-12. https:// doi.org/10.22004/ag.econ.190597

Ma, W. y Abdulai, A. (2016). Does cooperative membership improve household welfare? Evidence from apple farmers in China. Food Policy, 58, 94-102. https://doi.org/10.1016/j.foodpol.2015.12.002

Mabuza, M., Ortmann, G. y Wale, E. (2015). Development in Practice Collective action in small-scale mushroom production in Swaziland: does organizational form matter? Development in Practice, 25(7), 1025-1042. https://doi.org/10.1080/09614524.2015.1070791

Méndez, Y., Palencia, J., Hernández, K., Hernández, E. y Beltrán, J. D. (2013). Reacción de genotipos de ñame (dioscoreaspp) a la antracnosis (colletotrichumgloeosporioides). Temas Agrarios, (18), 34-40.

Mensah, E. R., Karantininis, K., Okello, J. J. y Karantininis, K. (2012). Determinants of Commitment to Agricultural Cooperatives: Cashew Nuts Farmers in Benin. International Association of Agricultural Economists (IAAE) Triennial Conference, Foz do Iguaçu, Brazil.

Munasib, A. y Jordan, J. (2011). The Effect of Social Capital on the Choice to Use Sustainable Agricultural Practices. Journal of Agricultural and Applied Economics, 43(2), 213-227. https://doi. org/10.1017/S107407080000417X

Nugusse, W. Z., Van Huylenbroeck, G. y Buysse, J. (2013). Determinants of rural people to join cooperatives in Northern Ethiopia. International Journal of Social Economics, 40(12), 1094-1107. https://doi.org/10.1108/IJSE-07-2012-0138

Ofuoku, A. U. y Urang, E. (2009). Effect of cohesion on loan repayment in farmers' cooperative societies in delta state, Nigeria. International Journal of Sociology and Anthropology, 1(4), 70-76.

Pinzón, Y., Bustamante, S. y Buitrago, G. (2013). Diagnóstico molecular diferencial Colletotrichumgloeosporioides y Fusarium oxysporum en ñame (Dioscoreasp.). Revista Colombiana de Biotecnología, 17(1), 52-60.

Putnam, R. (1993). The Prosperous Community: Social Capital and Public Life. The American Prospect, (13), 35-42.

Ramos, V., Bustamante, R., Rincón, J., Rojas, M., Raz, L. y Buitrago, G. (2015). Identificación, establecimiento in vitro y análisis fitoquímico preliminar de especies silvestres de ñame (Dioscoreaspp.) empleadas con fines medicinales. Revista Colombiana de Biotecnología, 17(1), 9-17. https://doi.org/10.15446/rev.colomb.biote.v17n1.50711

Reina, Y. (2012). El cultivo de ñame en el caribe colombiano. Documentos de trabajo sobre economía regional $n^{\circ}$ 168. Banco de la Republica. https://www.banrep.gov.co/sites/default/files/ publicaciones/archivos/dtser_168.pdf 
Revista Dinero. (2016). El ñame conquista los mercados externos. http://www.dinero.com/edicionimpresa/negocios/articulo/la-demanda-del-name-ha-crecido-en-los-consumidores-de-estadosunidos/223537

Rómulo, A. (2017). Determinantes del cooperativismo agrícola en la región Caribe (tesis de pregrado). Fundación Universidad del Norte, Barranquilla, Colombia.

Sykuta, M. y Chaddad, F. (1999). Putting theories of the firm in their place: A supplemental digest of the new institutional economics. Journal of Cooperatives, (14), 68-76. https://doi.org/10.22004/ ag.econ. 46368

Szabolcs, B., Eszter, H. y Katailn, R. (2016). Economic and social importance of vertical and horizontal forms of agricultural cooperation in Hungary. Studies in Agricultural Economics, 118(2), 77-84. https://doi.org/10.22004/ag.econ.246258

Vargas, G. (2002). Hacia una teoría del capital social. Revista de economía institucional, 4(6), 71-108.

Vázquez, A. (1999). Desarrollo, redes e innovación. Ediciones Pirámide.

Verhofstadt, E. y Maertens, M. (2015). Submitted Article Can Agricultural Cooperatives Reduce Poverty? Heterogeneous Impact of Cooperative Membership on Farmers' Welfare in Rwanda. Applied Economic Perspectives and Policy, 37(1), 86-106. https://doi.org/10.1093/aepp/ppuo21

Wossen, T., Abdoloulaye, T., Alege, A., Haile, M., Feleke, S., Olanrewaju, A. y Victor, M. (2017). Impact of extension access and cooperative membership on adoption technology house gold welfare. Journal of Rural Studies, 54, 223-233. https://doi.org/10.1016/j.jrurstud.2017.06.022

Zheng, S., Wang, Z. y Awokuse, T. O. (2012). Determinants of Producers' Participation in Agricultural Cooperatives: Evidence from Northern China. Applied Economic Perspectives and Policy, 34(1), 167186. https://doi.org/10.1093/aepp/ 